\title{
Biomineralization and Biomaterial Considerations in Dentin Remineralization
}

\author{
${ }^{1}$ Xu Zhang, ${ }^{2}$ Zuohui Xiao, ${ }^{3}$ Haorong Wang, ${ }^{4}$ Anil Kishen
}

\begin{abstract}
Dentin is a composite hard tissue, comprising of inorganic and organic matrices, and regulated by many proteins during development. The demineralization of dentin results from the loss of inorganic matrix [mainly hydroxyapatite (HAP)], but the organic matrix (mainly type I collagen) will sustain for a period of time after demineralization. Over the past decade, there has been a growing interest on the remineralization of demineralized dentin, primarily in connection with minimally invasive caries management. More and more biomaterials and methods are currently being evaluated to achieve newer approaches for the remineralization of demineralized dentin. These strategies are mostly based on biomimetic approaches and aim to achieve the characteristics of natural hard tissue. This article will present a complete review on the basic compositions and properties of dentin, which formed the basis for the biomimetic remineralization of demineralized dentin.
\end{abstract}

Keywords: Biomineralization, Collagen, Dentin, Noncollagenous proteins, Remineralization.

How to cite this article: Zhang $\mathrm{X}$, Xiao Z, Wang $\mathrm{H}$, Kishen A. Biomineralization and Biomaterial Considerations in Dentin Remineralization. J Oper Dent Endod 2016;1(1):7-12.

\section{Source of support: Nil}

Conflict of interest: None

\section{INTRODUCTION}

Management of demineralized dentin is an important issue in dentistry. Clinicians routinely favor removing the softened dentin completely based on the hypothesis that softened dentin is typically infected dentin. ${ }^{1}$ It is established that softening of dentin always precedes bacterial invasion and leaves a layer that is soft but not infected. This layer of demineralized dentin is thick in acute caries. ${ }^{2}$ The term remineralization of dental tissue refers to the replacement of the mineral fraction lost

${ }^{1}$ Associate Professor, ${ }^{2,3}$ Graduate Student, ${ }^{4}$ Professor and Head

${ }^{1-3}$ Department of Endodontics, School and Hospital of Stomatology, Tianjin Medical University, Tianjin, PR China

${ }^{4}$ Discipline of Endodontics, Faculty of Dentistry, University of Toronto, Toronto, Canada

Corresponding Author: Anil Kishen, Professor and Head Discipline of Endodontics, Faculty of Dentistry, University of Toronto, 124 Edward Street, Toronto, Ontario, Canada, e-mail: anil.kishen@utoronto.ca during the demineralization process. From a clinical standpoint, optimal remineralization of a demineralized dentin layer will aid in preventing/treating dentin caries, root caries, and dentin hypersensitivity. ${ }^{3}$ These strategies would serve as the foundation for minimally invasive approaches in the management of early dental caries.

Dentin remineralization is a complex process and most relevant research in dentin remineralization involves the understanding of the property of dentin matrix, the composition of remineralization solution and the interaction between the matrix and solution. In dentin matrix, besides inorganic fraction [mainly hydroxyapatite (HAP)], it also consists of significant levels of organic matrix that comprises of type I collagen and noncollagenous proteins (NCPs), such as dentin matrix protein (DMP1) and dentin phosphoprotein (DPP), also known as DMP2 or phosphophoryn, with highly phosphorylated serine and threonine residues. ${ }^{4}$ The NCPs has an important role in the mineralization of collagen fibrils. According to the location within the collagen fibrils, the apatite crystallites are classified into extrafibrillar minerals and intrafibrillar minerals. Extrafibrillar minerals are located in spaces separating the collagen fibrils, while the intrafibrillar minerals are largely in the gap regions of the fibrils extending between tropocollagen molecules. ${ }^{5-7}$

It is suggested that remineralization mechanisms in enamel and dentin are similar. ${ }^{8-11}$ Many studies have demonstrated that methods used in enamel remineralization would also work in case of dentin remineralization. A typical example for this is the application of fluoride. Currently, an accepted notion is that dentin remineralization occurs neither by spontaneous precipitation nor by nucleation of mineral on the organic matrix but by the growth of residual crystals in the lesions. ${ }^{3}$ However, the role of organic matrix in association with the residual crystals (inorganic matrix) on dentin remineralization is debated. It has been indicated that if NCPs, as inhibitors of mineralization are removed, mineralization would occur on the completely demineralized dentin substrate. ${ }^{3}$ On the other hand, Saito et $\mathrm{al}^{12}$ reported that if completely demineralized dentin collagen (by EDTA treatment) contains a higher content of ester phosphate, it would induce remineralization. In addition, Kawasaki et $\mathrm{al}^{3}$ have reported that the presence of fluoride could overcome the inhibitory effect of NCPs on mineralization. 
In dentin remineralization, the role of (a) inorganic matrix, (b) organic matrix, and (c) inorganic/organic additives in remineralization solution, needs to be further clarified. This knowledge would form the basis for newer methodologies for the remineralization of dentin or enamel. With improved understanding on the biomineralization of dentin and functions of NCPs, biomimetic strategies that are based on the interaction between organic macromolecules and inorganic/organic matrix could be developed for the remineralization of dental hard tissue. The advantage of biomimetic mineralization is that it simulates the natural process of formation of mineral crystals without using special equipment and strict conditions. ${ }^{13}$ Some biomimetic remineralizing agents have been developed, such as nanocomplexes of stabilizer and amorphous calcium phosphate (ACP). These nanocomplexes can remineralize enamel lesions, ${ }^{14}$ and when combined with a phosphorylated collagen, these nanocomplexes can remineralize dentin collagen as well ${ }^{15}$ These strategies would provide the foundation for the nondestructive and more efficient methodologies for the minimally invasive management of dental caries. This review will focus on the biomineralization of dentin and the role of inorganic/organic matrix constituents on dentin remineralization.

\section{BIOMINERALIZATION OF DENTIN}

The process of biomineralization of dentin involves the interaction of NCPs with collagen fibrils and minerals. ${ }^{16}$ The formation of dentin is a tissue-specific biomineralization process, which occurs at spatially independent sites throughout the organic extracellular matrices, mostly type I collagen fibrils and NCPs. The schematic drawing in Figure 1 depicts the highly polarized odontoblast with its process extending through the predentin into the dentin. ${ }^{17}$ The mineralization front follows the cell movement at the same rate, maintaining an essentially constant width of the unmineralized predentin. ${ }^{18}$ In predentin zone, the odontoblast actively secretes collagen to form collagen network and proteoglycan (PG). Several noncollagenous components, such as DPP, $\gamma$-carboxyglutamate-containing proteins of the osteocalcin type (Gla-protein) and a second pool of PG, are transported within the odontoblast process and secreted just in front of the advancing mineralized dentin. In the mineralization front, NCPs interacts with the collagen fibrils and inorganic ions to specifically trap calcium and phosphate ions to initialize mineralization. ${ }^{19-21}$ Furthermore, a second pool of PGs appeared to be involved in the nucleation, orientation and growth of HAP crystal. ${ }^{22-24}$ Dentin phosphoprotein is detected only in the dentin side of the mineralization front but not in predentin. ${ }^{25-29}$ Therefore, a possible role of DPP in dentin mineralization may be to regulate the growth of crystals behind the mineralization front.

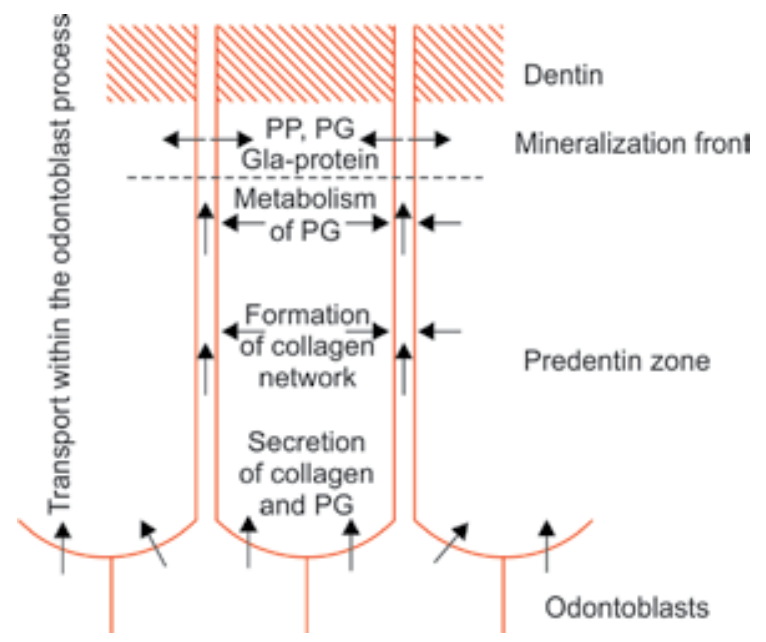

Fig. 1: Schematic drawing of the odontoblast-predentin region during dentinogenesis. Macromolecules are synthesized within the odontoblast cell bodies (below). The constituents of predentin, collagen, and proteoglycan (PG) are secreted close to the odontoblast cell bodies to form the extracellular, nonmineralized predentin matrix. Some of this proteoglycan fraction is metabolized in predentin. It should be noted that the 'mineralization front' is just an operative term, denoting that part of predentin where mineral formation is initiated ${ }^{17}$

Dentin collagen fibrils show a high degree of organization, a strong crystalline character and ability to interlock, which might be related to the specific type of NCPs that induced mineralization. ${ }^{24,30,31}$ In the beginning of the mineralization, the HAP crystals start in gap regions or attach to the collagen fibrils that work as a scaffold. On the other hand, the body fluid composed of extracellular and intracellular fluid is known as a source of calcium and phosphate in biomineralization, ${ }^{32}$ but the roles of other inorganic ions and organic macromolecules in body fluid and their synergism are not completely elucidated. It is considered that calcium ions are transported to the mineralization front by a transcellular route, where $\mathrm{Ca}^{2+-}$ activated ATPase, in concert with $\mathrm{Na}^{+} / \mathrm{Ca}^{2+-}$ exchangers, calcium channels and intracellular calcium binding proteins, maintain a delicate calcium ion homeostasis in odontoblasts. ${ }^{33-37}$ Phosphate ions are nonspecifically cleaved from compounds by alkaline phosphatase to support mineralization. Activity of alkaline phosphatase has been shown to increase at the mineralization front when crystal growth is occurring. ${ }^{38}$

Understanding the function of body fluid in biomineralization is significant for remineralization. Up to now, simulated body fluid has widely been used in the in vitro study of mimetic mineralization. What can be learned from biomineralization of dentin is that for remineralization of dentin or even for mimetic synthesis of other mineral crystals, the nucleation and regulation for morphology and structure in the crystal growth are crucial. Therefore, the study of biomimetic strategies should focus on these two following scenarios: 


\section{THE ROLE OF INORGANIC MATRIX OF DENTIN IN REMINERALIZATION}

In remineralization process, the nucleation of mineral crystals on inorganic matrix is a rate-determining step, which is driven by local $\mathrm{pH}$, supersaturation with respect to HAP, amount of seed crystals (nucleation sites) and surface area available for crystal growth. ${ }^{39}$ The process of remineralization of more advanced subsurface lesions, where the diffusion of lattice ions take place through the surface pores is also considered to be a rate-determining step. ${ }^{11}$ If the nucleation process occurs rapidly, the ions will be quickly depleted from the remineralization solution for nucleation and crystal growth. Consequently, a concentration gradient required for the diffusion will not occur and with progressive remineralization, the lesion pores may become blocked. ${ }^{39}$ Thus, lower concentrations of calcium and phosphate are often preferable in remineralization solution to prevent immediate precipitation, which hindered ions diffusion into the deeper aspect of the lesion.

During the process of repair of early dental caries, the nucleation of mineral crystals on organic matrix should exceed above rate maintaining the balance. To achieve this goal, some additives are introduced to remineralization system to enhance the nucleation rate of mineral crystals. Fluoride is one the most successfully used agent. This is because the solubility product constant of FAP is $7.08 \times$ $10^{-122} \mathrm{~mol}^{18} \cdot \mathrm{l}^{-18}$, ${ }^{40}$ which is less than that of HAP, $5.5 \times$ $10^{-118} \mathrm{~mol}^{18} \cdot .^{-18}$ at $37^{\circ} \mathrm{C}^{41}$ The former agent is thus more favorable than the latter. Consequently, the presence of fluoride in saliva, biofilm fluid and remineralization solution can enhance remineralization. ${ }^{42}$ In presence of fluoride, the nucleation and de novo formation of mineral crystals could occur, which could result in hyperremineralization. For this point, a lower concentration of fluoride is recommended.

\section{THE ROLE OF ORGANIC MATRIX OF DENTIN IN REMINERALIZATION}

The organic matrix of dentin primarily consists of fibrous collagens and NCPs. Collagen constitutes $90 \%$ of the dentin matrix, and is principally type I. ${ }^{43,44}$ Type I collagen itself in dentin does not seem to be able to induce significant remineralization of demineralized dentin ${ }^{11,39,45}$ but may act as a template for mineral deposition. ${ }^{46} \mathrm{NCPs}$ constitute the remaining $10 \%$ of the dentin organic matrix. It is worth noting that some studies ${ }^{4,11,20}$ indicated that NCPs in dentin could influence dentine remineralization by regulating the nucleation of mineral crystals. Hence, from the remineralization kinetic viewpoint, $\mathrm{NCPs}$ is also a rate-determining factor in nucleation of the mineral crystals during remineralization. Type I collagen in skin and tendon are not mineralized in vivo, where NCPs related to mineralization may be lacking or if present, may inhibit mineralization. Thus, it can be considered that collagen act as a foreign body/surface in vitro to induce nucleation based on the mechanism of heterogeneous nucleation. The carboxyl groups of collagen were considered to be the nucleation sites. ${ }^{47}$ These findings emphasize that collagen substrate along with certain NCPs induce mineral growth. ${ }^{48}$

The NCPs in the matrix of completely demineralized dentin collagen are not equal to that of fully mineralized dentin. The nature and mount of NCPs in demineralized dentin would depend upon the method of demineralization. Thus, promoter or inhibitor of NCPs,${ }^{49,50,51}$ and the presence of NCPs in partially and completely demineralized dentin influences its remineralizing capacity in vitro. The major components of NCPs in dentin are attributed to the SIBLING (small integrin-binding ligand, $\mathrm{N}$-linked glycoprotein) family, ${ }^{52}$ and their gene is all clustered within an approximately $375 \mathrm{~kb}$ span of nucleotides on human chromosome $4 \mathrm{q} 21$ (mouse 5q21). ${ }^{4}$ SIBLING family is composed of osteopontin (OPN), matrix extracellular phosphoglycoprotein (MEPE), bone sialoprotein (BSP), DMP1 and dentin sialophosphoprotein (DSSP). Osteopontin and MEPE acting as inhibitors of mineralization are found widely in mineralized and nonmineralized tissue, while DMP1 and the subdomains of DSSP [DSP (dentin sialoprotein), DGP (dentin glycoprotein) and DPP] are strongly engaged in bone and dentin mineralization. ${ }^{4}$ Among NCPs in dentin, the properties and behaviors in mineralization of DPP (DMP2) and DMP1 are the most documented. ${ }^{4}$

The role of DPP in mineralization process of calcium phosphate in vitro was the most exhaustively studied in the past three decades. Due to the application of different extraction methods and dentin source (human or animals), the DPP used in early studies were altered in molecular weight, type and content of amino acid. Despite these differences in DPP used in different studies, the enrichment of aspartic and serine, high phosphorylation of serines and (Asp-Ser-Ser) repeats are common characteristics. A typical human DPP is a $140 \mathrm{KDa}$ protein containing approx $38 \%$ aspartic acid and $42 \%$ serine. ${ }^{50,53}$ Phosphorylation of serine residues results in a very high negative charge molecule that can be considered a virtual sink for the binding of calcium ions. ${ }^{4}$ In vitro studies of DPP were shown to inhibit the formation of HAP de novo in solution, ${ }^{54}$ and gel systems ${ }^{55,56}$ but to promote HAP formation when it was covalently immobilized on agarose beads and collagen. ${ }^{57-59}$ These findings suggest that the formation of HAP is inhibited by soluble DPP but promoted by immobilized DPP. In addition, in the 
gel system the formation of HAP is independent on the concentration of DPP (decreasing by $100 \mu \mathrm{g} / \mathrm{ml}$ of DPP and increasing by $0.01-1 \mu \mathrm{g} / \mathrm{ml}){ }^{56}$ The inhibition or promotion of mineralization by free DPP in solution depends on its concentration, while immobilized DPP on a certain surface could induce mineralization. Furthermore, studies have shown that EDTA-soluble DPP, which are inhibitor of mineralization, when removed from dentin collagen, would facilitate remineralization of completely demineralized collagen. ${ }^{12,60,61,62,63}$

Dentin matrix protein was identified as a new serinerich acidic protein of the dentin matrix by cDNA cloning, containing 489 amino acid residues. ${ }^{49}$ Compared with DDP, DMP1 has a high content of Glu residues and does not contain $(\mathrm{DSS})_{\mathrm{n}}$ repeats. Dentine matrix protein is present in phosphorylated form at low levels in the dentine matrix as shown in immunochemical and organ culture biosynthetic studies. ${ }^{49}$ Its effect on remineralization of demineralized dentin has not been investigated, but its role in mineralization of collagen in vitro has been studied, which could suggest remineralization of dentin. He et al reported that two peptide clusters at C-terminal of DMP1, 349DSESSEEDR357 and 424EENRDSDSQDSSR437, were identified as collagen-interactive peptides. ${ }^{64}$ The binding between DMP1 and collagen is driven by electrostatic interaction as indicated by the acid residues in these two peptides. On the other hand, the N-terminal domain of DMP1 can stabilize ACP due to the high negative charge density created by aspartic acid residues that can favor and stabilize the amorphous nuclei. ${ }^{65}$ Nanocomplexes of DMP1/ACP as a precursor to apatite penetrates the gap zone of collagen and finally transform into HAP crystals to mineralize collagen. It was shown that DMP1 could serve dual roles during dentin formation: inhibiting spontaneous mineral precipitation and promoting controlled mineral nucleation on a collagenous template. ${ }^{65}$

Based on the stabilization effect of ACP by DMP1, analog materials that mimic DMP1 have been designed to simulate the remineralization function in dentin. These materials are equipped with high negative charge due to rich carboxyl groups, such as polyacrylic acid (PAA) and polyaspartic acid (PASA). ${ }^{15,66-68}$ While some other materials, such as phosphorylated chitosan (Pchi) and carboxymethyl chitosan (CMC) could not only stabilize ACP due to their charge characteristic, but also could be processed into scaffolds by lyophilization for certain specific clinical application. ${ }^{69-71}$ In summary, DPP and DMP1 play a dual role in mineralization. They can act as an inhibitor of crystal nucleation/growth in solution or as a template for crystal nucleation when immobilized on a solid surface. The mineralization of collagen based on the immobilization of DPP on collagen and the interaction of DMP1 with ACP and collagen would suggest a possibility for remineralizing the demineralized dentin.

\section{SUMMARY}

Improved understanding on the role of organic matrix in the biomineralizaton of dentin, highlighted that collagen could play a key role in the remineralization of dentin. Thus, remineralization could be achieved by modifying collagen, while dismissing the conventional concept of depending only on the inorganic matrix to induce remineralization of dentin. Therefore, remineralizing nanomaterials, especially biomimetic nanomaterials and their remineralizing rationale, would broaden the horizon in minimally invasive or microdentistry.

\section{REFERENCES}

1. Kato S, Fusayama T. Recalcification of artificially decalcified dentin in vivo. J Dent Res 1970;49(5):1060-1067.

2. Fusayama T, Okuse K, Hosoda H. Relationship between hardness, discoloration, and microbial invasion in carious dentin. J Dent Res 1966;45(4):1033-1046.

3. Kawasaki K, Ruben J, Stokroos I, Takagi O, Arends J. The Remineralization of EDTA-Treated Human Dentine. Caries Res 1999;33(4):275-280.

4. George A, Veis A. Phosphorylated Proteins and Control over Apatite Nucleation, Crystal Growth and Inhibition. Chem Rev 2008.

5. Arsenault AL. Crystal-collagen relationships in calcified turkey leg tendons visualized by selected-area dark field electron microscopy. Calcif Tissue Int 1988;43(4):202-212.

6. Traub W, Arad T, Weiner S. Three-dimensional ordered distribution of crystals in turkey tendon collagen fibers. Proc Nat Acad Sci 1989;86(24):9822-9826.

7. Landis WJ, Hodgens KJ, Arena J, Song MJ, McEwen BF. Structural relations between collagen and mineral in bone as determined by high voltage electron microscopic tomography. Microsc Res Tech 1996;33(2):192-202.

8. Levine R, Rowles S. Further studies on the remineralization of human carious dentine in vitro. Arch Oral Biol 1973;18(11): 1351-IN3.

9. Daculsi G, Kerebel B, Cabellec M, Kerebel L. Qualitative and Quantitative Data on Arrested Caries in Dentine. Caries Res 1979.

10. Stetler-Stevenson W, Veis A. Type I collagen shows a specific binding affinity for bovine dentin phosphophoryn. Calcified Tissue Int 1986;38(3):135-141.

11. Klont B, Ten Cate J. Remineralization of bovine incisor root lesions in vitro: the role of the collagenous matrix. Caries Res 1991;25(1):39-45.

12. Saito T, Yamauchi M, Crenshaw MA. Apatite induction by insoluble dentin collagen. J Bone Min Res 1998;13(2):265-270.

13. Zhang H, Liu J, Yao Z, Yang J, Pan L, Chen Z. Biomimetic mineralization of electrospun poly (lactic-co-glycolic acid)/ multi-walled carbon nanotubes composite scaffolds in vitro. Materials Letters 2009;63(27):2313-2316. 
14. Cross K, Huq N, Reynolds E. Casein phosphopeptides in oral health-chemistry and clinical applications. Curr Pharm Des 2007;13(8):793-800.

15. Tay FR, Pashley DH. Guided tissue remineralisation of partially demineralised human dentine. Biomaterials 2008;29(8):1127-1137.

16. Veis A. A Window on Biomineralization. Science 2005.

17. $\mathrm{Xu} \mathrm{Z}$. Understanding dentine demineralization and Development of Strategies for Biomimetic Remineralization of Demineralized Dentine: National University of Singapore; 2011.

18. Epple M. Biomineralization. From Biology to Biotechnology and Medical Application. Edited by Edmund Baeuerlein. Angewandte Chemie International Edition 2001.

19. Addadi L. Stereochemical and structural relations between macromolecules and crystals in biomineralization. Biomineralization, chemical and biochemical perspectives 1989:133-152.

20. Glimcher MJ. Mechanism of calcification: Role of collagen fibrils and collagen-phosphoprotein complexes in vitro and in vivo. The Anatomical Record 1989;224(2):139-153.

21. Goldberg M, Takagi M. Dentine proteoglycans: composition, ultrastructure and functions. Histochemical J 1993;25(11): 781-806.

22. Embery G, Hall R, Waddington R, Septier D, Goldberg M. Proteoglycans in dentinogenesis. Crit Rev in Oral Biol Med 2001;12(4):331-349.

23. Goldberg M, Rapoport O, Septier D, Palmier K, Hall R, Embery G, et al. Proteoglycans in predentin: the last 15 micrometers before mineralization. Connect Tissue Res 2003; 44(1):184-188.

24. Milan A, Sugars R, Embery G, Waddington R. Dentinal proteoglycans demonstrate an increasing order of affinity for hydroxyapatite crystals during the transition of predentine to dentine. Calcif Tissue Int 2004;75(3):197-204.

25. Weinstock M, Leblond C. Radioautographic visualization of the deposition of a phosphoprotein at the mineralization front in the dentin of the rat incisor. J Cell Biol 1973;56(3):838-845.

26. Carmichael D, Chovelon A, Pearson C. The composition of the insoluble collagenous matrix of bovine predentine. Calcif Tissue Res 1975;17(4):263-271.

27. Jontell M, Linde A. Non-collagenous proteins of predentine from dentinogenically active bovine teeth. Biochem J 1983; 214:769-776.

28. Takagi Y, Fujisawa R, Sasaki S. Identification of dentin phosphophoryn localization by histochemical stainings. Connect Tissue Res 1986;14(4):279-292.

29. Nakamura O, Gohda E, Ozawa M, Senba I, Miyazaki H, Murakami T, et al. Immunohistochemical studies with a monoclonal antibody on the distribution of phosphophoryn in predentin and dentin. Calcif Tissue Int 1985;37(5):491-500.

30. Habelitz S, Balooch M, Marshall SJ, Balooch G, Marshall GW. In situ atomic force microscopy of partially demineralized human dentin collagen fibrils. J Structural Biol 2002;138(3): 227-236.

31. Balooch M, Balooch G, Habelitz S, Marshall S, Marshall G, editors. Intrafibrillar demineralization study of single human dentin collagen fibrils by AFM. MRS Proceedings; 2004: Cambridge Univ Press.

32. Chave KE. Physics and chemistry of biomineralization. Annual Review of Earth and Planetary Sciences 1984;12:293.
33. Granström G, Linde A. ATP-dependent uptake of $\mathrm{Ca}^{2+}$ by a microsomal fraction from rat incisor odontoblasts. Calcif Tissue Int 1981;33(1):125-128.

34. Granström G. Further evidence of an intravesicular $\mathrm{Ca}^{2+-}$ pump in odontoblasts from rat incisors. Arch Oral Biol 1984;29(8):599-606.

35. Carafoli E. Intracellular calcium homeostasis. Annual Rev Biochem 1987;56(1):395-433.

36. Lundgren $\mathrm{T}$, Linde $\mathrm{A}$. $\mathrm{Na}+/ \mathrm{Ca}^{2+}$ antiports in membranes of rat incisor odontoblasts. J Oral Pathol Med 1988;17(9-10): 560-563.

37. Magloire H, Joffre A, Azerad J, Lawson D. Localization of $28 \mathrm{kDa}$ calbindin in human odontoblasts. Cell Tissue Res 1988;254(2):341-346.

38. Ten Cate A. Hard tissue formation and destruction. Oral histology: development, structure and function. 5th ed. Mosby, St Louis; 1998. p. 69-77.

39. Ten Cate J. Remineralization of caries lesions extending into dentin. J Dent Res 2001;80(5):1407-1411.

40. Larsen M, Nyvad B. Enamel erosion by some soft drinks and orange juices relative to their $\mathrm{pH}$, buffering effect and contents of calcium phosphate. Caries Res 1999;33(1):81-87.

41. Mann S, Webb J, Williams R. Biomineralization. New York VCH; 1989.

42. Cury J, Tenuta L. How to maintain a cariostatic fluoride concentration in the oral environment. Adv Dent Res 2008; 20(1):13-16.

43. Gage J. Electrophoretic characterization of peptides from normal mature human dentine. Arc Oral Bio 1984;29(8): 575-580.

44. Lukinmaa P-L, Waltimo J. Immunohistochemical localization of types I, V, and VI collagen in human permanent teeth and periodontal ligament. J Dent Res 1992;71(2):391-397.

45. Featherstone J. Fluoride, remineralization and root caries. Am J Dent 1994;7(5):271-274.

46. Kawasaki K, Featherstone J. Effects of collagenase on root demineralization. J Dent Res 1997;76(1):588-595.

47. Rhee SH, Lee JD, Tanaka J. Nucleation of hydroxyapatite crystal through chemical interaction with collagen. J Am Ceramic Soc 2000;83(11):2890-2892.

48. Koutsoukos P, Nancollas G. The mineralization of collagen in vitro. Colloids and Surfaces 1987;28:95-108.

49. George A, Sabsay B, Simonian P, Veis A. Characterization of a novel dentin matrix acidic phosphoprotein. Implications for induction of biomineralization. J Biol Chem 1993;268(17): 12624-12630.

50. Hunter G, Hauschka P, Poole A, Rosenberg L, Goldberg H. Nucleation and inhibition of hydroxyapatite formation by mineralized tissue proteins. Biochem J 1996;317:59-64.

51. He G, Ramachandran A, Dahl T, George S, Schultz D, Cookson D, et al. Phosphorylation of phosphophoryn is crucial for its function as a mediator of biomineralization. J Biol Chem 2005;280(39):33109-33114.

52. Fisher L, Torchia D, Fohr B, Young M, Fedarko N. Flexible structures of SIBLING proteins, bone sialoprotein, and osteopontin. Biochem Biophys Res Commun 2001;280(2): 460-465.

53. Chang S, Chiego D, Clarkson B. Characterization and identification of a human dentin phosphophoryn. Calcif Tissue Int 1996;59(3):149-153. 
54. Doi Y, Horiguchi T, Kim S-H, Moriwaki Y, Wakamatsu N, Adachi $\mathrm{M}$, et al. Effects of non-collagenous proteins on the formation of apatite in calcium $\beta$-glycerophosphate solutions. Arch Oral Biol 1992;37(1):15-21.

55. Fujisawa R, Kuboki Y. Preferential adsorption of dentin and bone acidic proteins on the (100) face of hydroxyapatite crystals. Biochimica et Biophysica Acta (BBA)-General Subjects 1991;1075(1):56-60.

56. Boskey AL, Maresca M, Doty S, Sabsay B, Veis A. Concentration-dependent effects of dentin phosphophoryn in the regulation of in vitro hydroxyapatite formation and growth. Bone Miner 1990;11(1):55-65.

57. Ganss C, Lussi A, Sommer N, Klimek J, Schlueter N. Efficacy of fluoride compounds and stannous chloride as erosion inhibitors in dentine. Caries Res 2010;44(3):248-252.

58. Linde A, Lussi A, Crenshaw MA. Mineral induction by immobilized polyanionic proteins. Calcif Tissue Int 1989;44(4): 286-295.

59. Doi Y, Horiguchi T, Kim S-H, Moriwaki Y, Wakamatsu N, Adachi M, et al. Immobilized DPP and other proteins modify OCP formation. Calcif Tissue Int 1993;52(2):139-145.

60. DeSteno C, Feagin F, Butler W. Mineralization of dentin, bone and tendonin vitro. Calcif Tissue Res 1975;17(2):161-163.

61. Oarkson B, Feagin F, McCurdy S, Sheetz J, Speirs R. Effects of phosphoprotein moieties on the remineralization of human root caries. Caries Res 1991;25(3):166-173.

62. Lussi A, Linde A. Mineral induction in vivo by dentine proteins. Caries Res 1993;27(4):241-248.

63. Clarkson B, Chang S, Holland G. Phosphoprotein analysis of sequential extracts of human dentin and the determination of the subsequent remineralization potential of these dentin matrices. Caries Res 1998;32(5):357-364.
64. He G, George A. Dentin matrix protein 1 immobilized on type I collagen fibrils facilitates apatite deposition in vitro. J Biol Chem 2004;279(12):11649-11656.

65. He G, Gajjeraman S, Schultz D, Cookson D, Qin C, Butler WT, et al. Spatially and temporally controlled biomineralization is facilitated by interaction between self-assembled dentin matrix protein 1 and calcium phosphate nuclei in solution. Biochemistry 2005;44(49):16140-16148.

66. Burwell AK, Thula-Mata T, Gower LB, Habeliz S, Kurylo M, Ho SP, et al. Functional remineralization of dentin lesions using polymer-induced liquid-precursor process. PloS one 2012;7(6):e38852.

67. Nudelman F, Pieterse K, George A, Bomans PH, Friedrich H, Brylka LJ, et al. The role of collagen in bone apatite formation in the presence of hydroxyapatite nucleation inhibitors. Nat Mater 2010;9(12):1004-1009.

68. Liu Y, Kim Y-K, Dai L, Li N, Khan SO, Pashley DH, et al. Hierarchical and non-hierarchical mineralisation of collagen. Biomaterials 2011;32(5):1291-1300.

69. Chen Z, Cao S, Wang H, Li Y, Kishen A, Deng X, et al. Biomimetic Remineralization of Demineralized Dentine using Scaffold of CMC/ACP Nanocomplexes in an in vitro Tooth Model of Deep Caries. PloS One 2015;10(1).

70. Zhang X, Li Y, Sun X, Kishen A, Deng X, Yang X, et al. Biomimetic remineralization of demineralized enamel with nano-complexes of phosphorylated chitosan and amorphous calcium phosphate. J Mater Sci Mater Med 2014;25(12): 2619-2628

71. Xu Z, Neoh KG, Lin CC, Kishen A. Biomimetic deposition of calcium phosphate minerals on the surface of partially demineralized dentine modified with phosphorylated chitosan. J Biomed Mater Res Part B: Appl Biomater 2011; 98(1):150-159. 